\title{
Expanding Indications for Liver Transplant: Tumor and Patient Factors
}

\author{
Kevin Ka-Wan Chu'1 , Kelly Hiu-Ching Wong², and Kenneth Siu-Ho Chok ${ }^{3}$ \\ ${ }^{1}$ Department of Surgery, ${ }^{2}$ Li Ka Shing Faculty of Medicine, and ${ }^{3}$ Department of Surgery and State Key Laboratory for Liver Research, \\ The University of Hong Kong, Hong Kong, China
}

\author{
Article Info \\ Received July 30, 2019 \\ Revised November 29, 2019 \\ Accepted November 29, 2019 \\ Published online February 28, 2020 \\ Corresponding Author \\ Kenneth Siu-Ho Chok \\ ORCID https://orcid.org/0000-0001-7921-3807 \\ E-mail kennethchok@gmail.com
}

\begin{abstract}
During the past few decades, liver transplant has developed from a high-mortality procedure to an almost routine procedure with good survival outcomes. The development of living donor liver transplant has increased the availability of liver grafts, and the scope of indications for liver transplant has been expanding ever since. The aim of this review is to provide an overview of such an expansion of scope. Various criteria have been proposed to expand the eligibility of patients with hepatocellular carcinoma exceeding the Milan criteria for liver transplant. Furthermore, liver transplant is increasingly performed as a treatment modality for cholangiocarcinoma, neuroendocrine liver metastasis and colorectal liver metastasis. The number of elderly patients receiving liver transplant is on the rise. Combined organ transplantation has also been adopted to treat patients with multiple organ failure. Going forward, further development of preoperative noninvasive predictors in tumor, patient and even donor factors is needed to identify patients at risk of poor outcomes and hence optimize patient management. (Gut Liver 2021;15:19-30)
\end{abstract}

Key Words: Liver transplant; Hepatocellular carcinoma; Surgical indication

\section{INTRODUCTION}

Liver transplant is one of the most effective treatments for irreversible acute or chronic liver failure and liver diseases with different causes when liver resection is contraindicated. During the past four decades, liver transplant has developed from a high-mortality procedure to an almost routine procedure with good survival outcomes, i.e. $>80 \%$ at 1 year and $>70 \%$ at 5 years. ${ }^{1,2}$ At the same time, living donor liver transplant was developed in the background of organ shortage $^{3-5}$ and has greatly expanded the availability of liver grafts. With various methods to increase graft availability together with improvement in patient outcomes, the scope of indications for liver transplant is expanding.

Hepatocellular carcinoma (HCC) is the commonest malignant indication for liver transplant. Starzl et al. ${ }^{6}$ described the first successful liver transplant as an oncological treatment for hepatoblastoma in 1967. Early attempts at using liver transplant to treat cholangiocarcinoma were disappointing. Better results were reported with more specific patient selection. ${ }^{7,8}$ In the past, metastatic liver dis- ease was a contraindication to liver transplant. Nowadays, liver transplant for diseases such as neuroendocrine liver metastasis, ${ }^{9-11}$ colorectal liver metastasis, ${ }^{12,13}$ etc. is being considered because of the slow-growing nature of these tumors. However, these indications are not favored by the transplant community when the shortage of liver grafts is concerned, especially in Asian places where liver graft shortage is grave (e.g., Hong Kong). In these places, the main concern about offering liver transplant to patients with neuroendocrine or colorectal liver metastasis would be the potential impact on other patients on local liver transplant waiting lists.

Liver transplant is an ultra-major surgery, and hence it was considered to be relatively contraindicated when the patients had high-risk factors for ultra-major surgery. ${ }^{14}$ However, with improvement in general outcomes, highrisk patients who have an advanced age, ultra-high Model of End-Stage Liver Disease (MELD) scores or co-morbidities are now potential candidates for liver transplant. In more extreme cases, combined organ transplant is a measure to treat multiple organ failure. ${ }^{15-17}$ 
The aim of this review is to give an overview of the expansion of liver transplant indications. In particular, the discussion will focus on the role of tumor factors and patient factors in determining eligibility for liver transplant.

\section{TUMOR FACTORS}

\section{HCC exceeding the Milan criteria}

Since the introduction of the Milan criteria by Mazzaferro et al. in 1996, ${ }^{18}$ it has been considered the gold standard for selection of HCC patients for liver transplant. The Milan criteria, defined as the presence of a tumor $5 \mathrm{~cm}$ or less in patients with single HCCs and no more than three tumor nodules, each $3 \mathrm{~cm}$ or less in diameter in patients with multiple tumors, has been validated by numerous studies over the past years. In a meta-analysis performed in 2011 including 19 studies conducted in 15 years on Milan criteria, ${ }^{19}$ it was concluded that significantly increased posttransplant survival was expected for patients who met the Milan criteria when compared with those who did not. A hazard ratio of 1.68 confirmed the inferior survival of patients beyond the Milan criteria when compared with patients within the criteria. However, over the past 20 years, the transplant community has come to realized that the Milan criteria are too restrictive, especially in the context of living donor liver transplant. Numerous centers have attempted to expand the Milan criteria through performing liver transplant for patients beyond the Milan criteria and evaluating the outcomes in these patients. These new criteria are summarized in Table 1.

Several groups have proposed new criteria featuring the expansion of the size and number of tumor nodules accepted on the basis of the Milan criteria. The University of California San Francisco (UCSF) criteria are the earliest and most well-known in this category. ${ }^{20}$ In the study, 70 HCC patients receiving liver transplant were retrospectively analyzed. It was found that patients meeting the criterion of solitary tumor $\leq 6.5 \mathrm{~cm}$ or $\leq 3$ nodules with the largest lesion $\leq 4.5 \mathrm{~cm}$ and total tumor diameter $\leq 8 \mathrm{~cm}$ had 1- and 5-year survival rates of $90 \%$ and $75.2 \%$ respectively; on the other hand, the 1-year survival rate was 50\% for patients beyond this criterion. The UCSF criteria were defined on the basis of explant histology findings, so the same group conducted a prospective study to validate the UCSF criteria on the basis of pretransplant imaging. ${ }^{21}$ The UCSF criteria were subsequently validated by Patel et al. in 2012. ${ }^{22}$ It was demonstrated that patients within the Milan criteria and patients within the UCSF criteria had similar overall survival. Thereafter, other criteria including the Hangzhou criteria and the Tokyo criteria were developed and validated over the years. ${ }^{23-27}$ The Hangzhou criteria were shown to provide an expansion rate of $51.5 \%$ when compared with the Milan criteria, while the overall and tumor-free survival rates were not significantly different. ${ }^{28}$

Portal vein tumor thrombus (PVTT) has been considered a contraindication to liver transplant due to the high risk of posttransplant intrahepatic recurrence or extrahepatic metastasis. ${ }^{29}$ However, recent studies in South Korea have expanded the indications for living donor liver transplant to include patients with PVTT. ${ }^{30-32}$ Lee et al. ${ }^{32}$ from Seoul National University Hospital investigated the outcomes of 11 patients diagnosed with HCC and PVTT who had received liver transplant and analyzed the risk factors for recurrence. The 1-, 3-, and 5-year recurrence-free survival rates were $63.3 \%, 45.5 \%$ and $45.5 \%$ respectively. Main portal vein invasion and high alpha-fetoprotein $\times$ protein induced by vitamin $\mathrm{K}$ absence/antagonist-II (AP score) $\geq 20,000$ were identified as significant risk factors for recurrence. It was therefore suggested that living donor liver transplant can be considered as a curative treatment option for patients with PVTT with careful selection of patients with a low AP score and PVTT not extending to the main portal vein. Similarly, studies from Seoul St. Mary's Hospi$\operatorname{tal}^{30}$ and Soonchunhyang University Seoul Hospital ${ }^{31}$ also concluded that, with careful selection criteria, living donor liver transplant can be offered to patients with PVTT.

Biochemical parameters such as alpha-fetoprotein (AFP) and protein induced by vitamin $\mathrm{K}$ absence or antagonistII (PIVKA-II) levels are included in several proposed selection criteria. ${ }^{27,33-35}$ Serum AFP has been increasingly recognized as a marker for poor prognosis after liver transplant. An AFP level $>1,000 \mathrm{ng} / \mathrm{mL}$ has been identified as a surrogate for vascular invasion and significant predictor of HCC recurrence after transplant. ${ }^{36}$ AFP is therefore incorporated in a few selection criteria including the 5-5-500 rule, ${ }^{35}$ which defines the eligibility criteria as tumor diameter $\leq 5 \mathrm{~cm}$, tumor number $\leq 5$ and serum AFP level $\leq 500$ $\mathrm{ng} / \mathrm{mL}$. Using the 5-5-500 rule, the study recorded a 5-year recurrence rate of $7.3 \%$ (95\% confidence interval, $5.2 \%$ to $9.3 \%$ ), and the rule provided a $19 \%$ increase in the number of patients eligible for transplant when compared with the Milan criteria. The 5-year overall survival rate was $75.8 \%$ for patients within the 5-5-500 rule. The Samsung criteria ${ }^{34}$ have parameters similar to the 5-5-500 rule but the cutoffs are higher, allowing a maximum tumor size of $\leq 6 \mathrm{~cm}$, tumor number of $\leq 7$ and AFP level of $\leq 1,000 \mathrm{ng} / \mathrm{mL}$. Interestingly, the 1-, 3-, 5-year overall survival rates of patients meeting the Samsung criteria were $97.9 \%, 91.5 \%$ and $90 \%$ respectively, which were higher than those reported in the 5-5-500 study despite much more lenient cutoffs. Further research on AFP cutoff level that would optimize patient 
Table 1. Expansion in Liver Transplant for HCC Exceeding the Milan Criteria

\begin{tabular}{|c|c|c|}
\hline Strategy & Criteria and validation studies & Key points \\
\hline The gold standard & $\begin{array}{l}\text { Milan criteria }{ }^{18} \\
\text { Validation: meta-analysis of } 25 \text { studies by } \\
\text { Mazzaferro et al. }{ }^{19}\end{array}$ & $\begin{array}{l}\text { Single tumor } \leq 5 \mathrm{~cm} \text {, or } \\
\text { No more than } 3 \text { tumor nodules, each } \leq 3 \mathrm{~cm} \\
\text { No extrahepatic manifestations } \\
\text { No evidence of gross vascular invasion }\end{array}$ \\
\hline \multirow[t]{5}{*}{$\begin{array}{l}\text { Expansion in size } \\
\text { and number }\end{array}$} & $\begin{array}{l}\text { University of California, San Francisco (UCSF) Criteria }{ }^{20} \\
\text { Validation: Yao et al., }{ }^{21} \text { Patel et al., }{ }^{22} \text { Unek et al. }{ }^{114}\end{array}$ & $\begin{array}{l}\text { Solitary tumor } \leq 6.5 \mathrm{~cm} \text {, or } \\
\leq 3 \text { Nodules with the largest lesion } \leq 4.5 \mathrm{~cm} \text { and total tumor } \\
\text { diameter } \leq 8 \mathrm{~cm}\end{array}$ \\
\hline & $\begin{array}{l}\text { Hangzhou criteria }{ }^{27} \\
\quad \text { Validation: Xu et al. }\end{array}$ & $\begin{array}{l}\text { One of the following two items; } \\
\text { Total tumor diameter } \leq 8 \mathrm{~cm} \\
\text { Total tumor diameter }>8 \mathrm{~cm} \text {, with histopathologic grade I or II and } \\
\text { preoperative AFP level } \leq 400 \mathrm{ng} / \mathrm{mL} \text {, simultaneously }\end{array}$ \\
\hline & $\begin{array}{l}\text { Tokyo criteria }(5-5 \text { rule })^{26} \\
\text { Validation: Togashi et al. }{ }^{115}\end{array}$ & $\begin{array}{l}\leq 5 \text { Nodules } \\
\text { Maximum tumor diameter of } 5 \mathrm{~cm}\end{array}$ \\
\hline & $\begin{array}{l}\text { Asan criteria }{ }^{24} \\
\quad \text { Validation: Bonadio et al. }{ }^{116}\end{array}$ & $\begin{array}{l}\text { Largest tumor diameter } \leq 5 \mathrm{~cm} \\
\mathrm{HCC} \text { number } \leq 6 \\
\text { No gross vascular invasion }\end{array}$ \\
\hline & $\begin{array}{l}\text { Up-to-seven criteria (new Milan criteria) } \\
\text { Validation: de Ataide et al. }{ }^{117}\end{array}$ & Size of largest tumor (in $\mathrm{cm}$ ) plus number of tumors $\leq 7$ \\
\hline \multirow[t]{3}{*}{$\begin{array}{l}\text { Presence of portal } \\
\text { vein invasion }\end{array}$} & Seoul St. Mary's Hospital ${ }^{30}$ & $\begin{array}{l}\text { Segmental portal vein tumor thrombus is acceptable, } \\
\text { especially when AFP }<100 \mathrm{ng} / \mathrm{mL} \\
\text { Lobar portal vein tumor thrombus remains a contraindication to } \\
\text { liver transplant }\end{array}$ \\
\hline & Seoul National University Hospital ${ }^{32}$ & $\begin{array}{l}\text { Living donor liver transplant could be considered if } \\
\text { - portal vein tumor thrombus does not extend into the main } \\
\text { portal vein } \\
\text { - AFP }\end{array}$ \\
\hline & Soonchunhyang University Seoul Hospital ${ }^{31}$ & $\begin{array}{l}\text { Living donor liver transplant could be considered if } \\
\text { - portal vein tumor thrombus is less than Vp4 type } \\
\text { (presence of tumor thrombus in the main truck of the portal } \\
\text { vein or a portal vein branch contralateral to the primarily } \\
\text { involved lobe, or both) } \\
\text { - showed good response to radiotherapy down-staging }\end{array}$ \\
\hline \multirow[t]{3}{*}{$\begin{array}{l}\text { Addition of bio- } \\
\text { chemical markers }\end{array}$} & $5-5-500$ Rule $^{35}$ & $\begin{array}{l}\text { Nodule size } \leq 5 \mathrm{~cm} \text { in diameter } \\
\text { Nodule number } \leq 5 \\
\text { AFP } \leq 500 \mathrm{ng} / \mathrm{mL}\end{array}$ \\
\hline & $\begin{array}{l}\text { Kyoto criteria } \\
\text { Validation: Kaido et al. }{ }^{118}\end{array}$ & $\leq 10$ Tumor nodules, and all $\leq 5 \mathrm{~cm}$, and PIVKA- $\| \leq 400 \mathrm{mAU} / \mathrm{mL}$ \\
\hline & Samsung criteria ${ }^{34}$ & $\begin{array}{l}\text { Maximal tumor size } \leq 6 \mathrm{~cm} \\
\text { Tumor number } \leq 7 \\
\text { AFP levels } \leq 1,000 \mathrm{ng} / \mathrm{mL}\end{array}$ \\
\hline Down-staging & Parikh et al.. ${ }^{37}$ Lei et al.. ${ }^{119}$ Yao et al. ${ }^{38}$ & $\begin{array}{l}\text { The success rate of down-staging to within Milan criteria } \\
\text { exceeds } 40 \%{ }^{37} \\
\text { Recipients who meet Milan or UCSF criteria after successful } \\
\text { down-staging achieve similar results to recipients } \\
\text { fulfilling the criteria without down-staging } \\
38,119\end{array}$ \\
\hline
\end{tabular}

HCC, hepatocellular carcinoma; AFP, alpha-fetoprotein; PIVKA-II, protein induced by vitamin K absence or antagonist-II.

outcomes is required. The Kyoto criteria include PIVKAII level as part of the criteria as PIVKA-II level $>400 \mathrm{mAU} /$ $\mathrm{mL}$ has been identified as an independent risk factor for postoperative recurrence.

Down-staging has been proposed as a method to expand the eligibility of HCC patients for liver transplant. Down-staging can be defined as a reduction in tumor burden using locoregional therapy to reduce tumor stage to within eligibility criteria for liver transplant. A meta-anal- ysis performed by Parikh et al..$^{37}$ reported that the pooled success rate of down-staging was $48 \%$ and the pooled posttransplant HCC recurrence rate was 16\%. In an intentionto-treat analysis, ${ }^{38}$ it was found that successful downstaging of HCC to within the Milan criteria resulted in a 5 -year survival rate of $77.8 \%$, which is comparable to the $81 \%$ reported in patients already within the Milan criteria without down-staging. These results have demonstrated that down-staging may be a potential method to further 
expand liver transplant indications in HCC patients beyond defined criteria.

\section{Cholangiocarcinoma}

Cholangiocarcinoma is a malignant tumor of the biliary system and is the second commonest primary liver cancer after HCC. ${ }^{39}$ Depending on its location, it can be classified as hilar cholangiocarcinoma, intrahepatic cholangiocarcinoma or distal cholangiocarcinoma (mid-third and lowerthird of the bile duct). ${ }^{40}$

Hilar cholangiocarcinoma carries a poor prognosis; the overall survival was reported to be between 12 and 24 months. ${ }^{41}$ Although the most promising treatment is complete resection with negative oncological margin, this could only be achieved in one-third of the patients. ${ }^{42-44}$ The low resection rate gave rise to the concept of treating these patients with liver transplant, which would be a cure for patients with unresectable hilar cholangiocarcinoma or insufficient liver reserve. However, early attempts of liver transplant alone as treatment of cholangiocarcinoma resulted in disappointing results, with a 5-year survival of $23 \%$ to $30 \%$ only. 45,46

Neoadjuvant therapy before liver transplant has been shown to result in improved survival outcomes. Nebraska University was among the first to offer neoadjuvant therapy to patients with hilar cholangiocarcinoma before liver transplant. ${ }^{47}$ Although the number of patients in the study was small $(n=17)$, this was the first study to report favorable long-term survival in selected patients with unresectable hilar cholangiocarcinoma; $45 \%$ of the transplant recipients were alive with a median follow-up period of 7.5 years. The Mayo Clinic group reported their series with neoadjuvant therapy followed by liver transplant in $2000 .^{7}$ This led to the development of the Mayo Clinic protocol, which includes selection of patients without evidence of metastatic or nodal disease, neoadjuvant highdose radiotherapy, and operative staging followed by liver transplant. ${ }^{48}$ With the neoadjuvant protocol consisting of a combination of external beam and transcatheter radiation with intravenous 5-fluorouracil, only one out of 11 transplant recipients had tumor relapse. It was thus concluded that liver transplant in combination with preoperative irradiation and chemotherapy might be a potential treatment for patients with early-stage cholangiocarcinoma. In an early study comparing liver resection and liver transplant, the 5 -year survival rate was $21 \%$ in the resection group and $82 \%$ in the transplant group with neoadjuvant chemoradiation. ${ }^{49}$ More recent publications from the Mayo Clinic reported 2- and 5-year recurrence-free survival rates of $78 \%$ and $65 \%$ respectively ${ }^{50}$ with the adoption of the Mayo Clinic protocol. Hong et al..$^{51}$ identified the lack of neoad- juvant and adjuvant therapy as an independent predictor of tumor recurrence after liver transplant for cholangiocarcinoma.

The Mayo Clinic protocol has received criticism as it includes two separate components which may affect survival results, namely, strict selection criteria and neoadjuvant therapy. A study by Mantel et al. ${ }^{52}$ investigated the effect of strict selection on patient survival. They looked into the survival outcomes in patients who were selected based on the Mayo Clinic protocol and received no neoadjuvant therapy. The 5-year survival of this subgroup of patients was $59 \%$, suggesting that selection criteria alone could result in improved survival when compared with results reported by early studies.

Table 2 is a summary of survival outcomes of liver transplant for hilar cholangiocarcinoma in studies with different neoadjuvant and selection protocols. As shown, combination of strict selection criteria and neoadjuvant therapy may achieve acceptable long-term survival in patients with hilar cholangiocarcinoma. Hence, hilar cholangiocarcinoma should not be an absolute contraindication to liver transplant. However, most of the studies were retrospective in nature and had small sample sizes. Further studies are required to elucidate the effect of neoadjuvant therapy followed by liver transplant on survival outcomes. In fact, this is already under investigation in the TRANSPHIL study (Randomized Prospective Multicentric Study: Liver Resection versus Radio-chemotherapy-Transplantation for Hilar Cholangiocarcinoma), which is expected to be completed in 2021. Furthermore, most of the studies were conducted in the West-in the East, liver transplant has not been widely adopted as a treatment of cholangiocarcinoma. Future studies exploring liver transplant as a treatment option for cholangiocarcinoma in Eastern populations would provide more evidence on the efficacy of this treatment modality.

Intrahepatic cholangiocarcinoma is a contraindication to liver transplant at most liver transplant centers around the world ${ }^{53}$ because of the very poor outcomes in the early experience of liver transplant for this disease. ${ }^{54,55}$ A Spanish multicenter study reported a reasonable outcome with a $73 \% 5$-year survival ${ }^{8}$ in a subgroup of very early intrahepatic cholangiocarcinoma $(\leq 2 \mathrm{~cm})$. However, the number of patients with this stage of disease was limited. In the same cohort, the outcome for combined HCC-cholangiocarcinoma had a better survival outcome, i.e. comparable with HCC patients. The authors concluded that a preoperative biopsy resulting in a diagnosis of combined HCCcholangiocarcinoma should not exclude patients from liver transplant.

Another role of liver transplant in this group of diseases is the liver transplant for patients with primary sclerosing 
cholangitis (PSC). Historically, PSC patients who developed cholangiocarcinoma while waiting for liver transplant had a poor prognosis and this is a relative contraindication to liver transplant in many programs. However, it was reported that the incidentally discovered tumors in the setting of PSC had good results without recurrence. ${ }^{7,56}$

\section{Neuroendocrine liver metastasis}

Neuroendocrine tumor metastasis localized to the liver is an indication for liver transplant as it is slow-growing and has lower oncological aggressiveness compared with HCC. ${ }^{9}$ In view of the scarcity of donated organs and improved results of nonsurgical treatment of neuroendocrine liver metastasis, the controversy over patient selection and timing for liver transplant continues. Patients who have neuroendocrine liver metastasis usually receive multimodal treatment including a combination of surgical resection, systemic chemotherapy, radiofrequency ablation, and transarterial chemoembolization. While complete resection is considered the only curative treatment, theoretically liver transplant would be the best treatment. It would be important to exclude other extrahepatic metastases-distant lymph nodes (20\% to $30 \%)$, peritoneal carcinomatosis $(10 \%$ to $33 \%$ ), lungs ( $3 \%$ to $5 \%$ ), and bones ( $1 \%$ to $6 \%)^{57}$

In a study comparing transplant with non-transplant treatment, the two groups of patients had similar 5-year overall survival but the transplant group had better 5 -year disease-free survival (50\% vs $34 \%$ ). ${ }^{58,59}$ There is the criticism that comparison of patients from the date of liver transplant is unfair as these patients had already undergone other therapy ${ }^{60}$ comparison at the time of diagnosis or the detection of uncontrolled disease would be fairer.

A systematic review conducted by Moris et al. ${ }^{61}$ in 2017 summarized 64 studies evaluating the outcomes of liver transplant for neuroendocrine tumor liver metastasis. Pancreas was the found to be the most common primary tumor site. The overall recurrence rate after liver transplant ranged from $31.3 \%$ to $56.8 \%$. The 5 -year overall survival rate ranged from $50 \%$ in multicenter studies to $70.7 \%$ in aggregated data from 57 single-center studies. The authors thus concluded that liver transplant offered survival benefits to patients with diffuse neuroendocrine metastases to the liver without extrahepatic disease. They further recommended that strict selection of patients would be required in order to optimize outcomes in the face of organ shortage.

The reported prognostic factors for tumor recurrence and poor overall survival were age $>50$ years, symptomatic tumor, primary tumor in the pancreas or a non-gastrointestinal location, non-carcinoid tumor, high Ki-67 index, involvement of liver more than $50 \%$, and poor tumor differentiation. ${ }^{9-11,59,62}$ The Milan criteria group thus suggested 
the "Milan criteria in case of Neuroendocrine Tumor (Milan-NET)" in 2007. ${ }^{62}$ The inclusion criteria for liver transplant include confirmed histology of low-grade (G1/ G2 grading according to the World Health Organization classification) neuroendocrine tumor, primary tumor removed with curative resection, metastatic diffusion to liver parenchyma $\leq 50 \%$, stable disease for at least 6 months before liver transplant, and age $\leq 55$ years. Application of the Milan-NET criteria resulted in 5-year and 10-year survival rates of $97 \%$ and $89 \%$ respectively. ${ }^{63}$ The same study also compared transplant for neuroendocrine liver metastasis and transplant for HCC and found comparable results between them.

The data presented above suggested that stringent criteria for selection of patients with good prognostic factors for liver transplant would result in favorable long-term survival comparable with that of HCC patients. On the other hand, disease down-staging ${ }^{64}$ and transplant delay ${ }^{62}$ were also proposed. From current evidence, neuroendocrine tumor is not an absolute indication for liver transplant. However, liver transplant for neuroendocrine liver metastasis was still uncommonly performed due to limited available data. In addition, most of the studies identifying prognostic variables and evaluating survival outcomes in the context of liver transplant for neuroendocrine metastasis were retrospective in nature. Future prospective studies with larger sample sizes are needed to further optimize the patient selection criteria for liver transplant for metastatic neuroendocrine tumors so that the benefit of liver transplant for this subgroup of patients can be maximized.

\section{Colorectal liver metastasis}

Colorectal cancer is one of the commonest cancer and a leading cause of cancer-related morbidity and death. ${ }^{65}$ Liver metastases are commonly detected as synchronous or metachronous lesions. ${ }^{66}$ Early attempts of liver transplant for these patients were disappointing. The first and largest published series from University of Vienna reported that the overall survival rates at 1,3 and 5 years were $76 \%, 32 \%$ and $12 \%$ respectively. ${ }^{67,68}$ Other early studies in the 1990 s also reported poor overall survival. ${ }^{69,70}$

In 2013, Hagness et al. ${ }^{12}$ from reported the outcomes of liver transplant for colorectal liver metastasis at Oslo University Hospital. Unlike Asian regions, Norway had a surplus of deceased donor liver grafts and the average waiting time for liver transplant was less than 1 month. ${ }^{12,13} \mathrm{~A}$ substantial number of liver grafts were exported to other liver transplant centers. They performed liver transplant for patients who met these three criteria: their primary tumors had been excised, their metastatic disease was confined to the liver, and they had undergone at least 6 weeks of chemotherapy. The overall survival rates at 1, 3 and 5 years were $95 \%, 68 \%$ and $60 \%$ respectively. Although the overall survival results were encouraging, almost all these patients had disease recurrence after 2 years from liver transplant. Risk factors for poor survival were largest tumor diameter, carcinoembryonic antigen, time from primary surgery, and nonresponse to chemotherapy. Four years later, Toso et al. ${ }^{13}$ reported a series of 12 liver transplants for colorectal liver metastasis at four European centers. The overall survival rates at 1,3 , and 5 years were $83 \%, 62 \%$, and $50 \%$ respectively, and only half of their patients had disease recurrence. Most of the patients who had synchronous metastasis received chemotherapy. All patients received a complex chemotherapy regimen and responded to chemotherapy. Predictive factors for poor disease-free survival were upfront transplant, salvage transplant, and vena cava involvement.

Liver transplant for colorectal liver metastasis is still highly controversial. With further improvement of chemotherapy, the results of treatment of colorectal liver metastasis may further improve. The role of liver transplant in the management of this disease will be redefined in the future.

\section{Other neoplasms}

Hepatoblastoma is the most common primary liver malignancy in children. The major treatment modalities for hepatoblastoma are chemotherapy and liver resection. However, for tumors involving all four sections, centrally located tumor which is not feasible for resection, portal vein, and hepatic vein involvement, liver transplant would be indicated. ${ }^{71,72}$ Long-term survival was reported to be $85 \%-90 \%{ }^{73}$

Epithelioid hemangioendothelioma is a rare tumor of vascular origin. Some hepatic epithelioid hemangioendotheliomas behave similarly to benign hepatic hemangiomas, whereas others have a clinical course resembling highly aggressive angiosarcoma. ${ }^{74}$ With data from United Network for Organ Sharing (UNOS), Rodriguez et al. ${ }^{74}$ analyzed the outcomes in 110 hemangioendothelioma patients having liver transplant between 1987 and 2005. The 1- and 5-year patient survival rates were $80 \%$ and $64 \%$ respectively and the 1 - and 5-year graft survival rates were $70 \%$ and $55 \%$ respectively. ${ }^{74}$ A more recent study conducted by Lai et al. ${ }^{75}$ demonstrated even more favorable survival outcomes. They retrospectively analyzed data from 1984 to 2014 in the European Liver Transplant Registry and found that the 1-, 5- and 10-year overall survival rates in the 149 patients having liver transplant for hepatic hemangioendothelioma were $88.6 \%, 79.5 \%$ and $74.4 \%$ respectively. They also identified the following three independent risk factors for recurrence: macrovascular 
invasion, hilar lymph node invasion, and a wait for transplant of $\leq 120$ days. These studies confirmed the value of liver transplant for patients with hemangioendothelioma. Unresectable hemangioendothelioma should therefore not be a contraindication to liver transplant. Prospective analyses are needed to determine the independent risk factors for survival of this subgroup of patients and to identify patients at risk of recurrence after liver transplant.

\section{PATIENT FACTORS}

\section{Age}

Advanced age was considered a relative contraindication to liver transplant as it is a major risk factor in many chronic diseases. ${ }^{76}$ However, as the population continues to age and good antiviral treatment delayed cirrhosis process, the proportion of elderly patients requiring liver transplant is expected to increase. ${ }^{77-79}$ Compared to the young, elderly patients more commonly present with co-morbidities including cardiovascular diseases, diabetes mellitus, renal insufficiency and pulmonary diseases, which adversely affect long-term prognosis. ${ }^{80}$ However, elderly recipients have been reported to display a lower rate of rejection with respect to immune senescence, ${ }^{81,82}$ which may indicate a favorable effect on graft survival.

There have been a few studies conducted to compare elderly and young transplant recipients in terms of postoperative outcomes and long-term survival. ${ }^{81-87}$ The results reported were inconsistent, which was likely in part due to the heterogeneity of age cutoffs for the elderly and nonelderly (varying between 60 and 75 years). Some studies reported comparable patient and graft survival rates between the two groups, ${ }^{82,83,85}$ while some reported significantly worse survival in the elderly group. ${ }^{81,84,86,87}$

One of the studies reporting inferior outcomes in elderly transplant recipients was a large retrospective study conducted by the University of California. The study compared 3,711 transplant recipients aged $\geq 60$ years and 11,966 recipients younger than 60 years. ${ }^{87}$ It was found that age $\geq 70$ years was independently associated with an increased risk of graft loss (hazard ratio, 1.65; 95\% confidence interval, 1.08 to $1.82 ; \mathrm{p}<0.001)$. However, the increased risk was attenuated in elderly patients with a MELD score $<28$. It was thus concluded that patients should not be excluded solely because of age. Similarly, preoperative intensive care unit admission, ${ }^{85}$ fulminant hepatic failure, ${ }^{85}$ pretransplant hospital admission ${ }^{86}$ and high bilirubin level ${ }^{86}$ were identified as independent risk factors for inferior outcomes in elderly patients.

Currently in the literature, the results of studies of liver transplant for the elderly are inconsistent. However, almost all studies concluded that age alone should not be an exclusion factor for liver transplant. For optimization of patient selection and graft allocation, further prospective studies should be conducted to identify the risk factors in elderly patients.

\section{Co-morbidity}

Patients with failure of another organ in addition to the liver may need a transplant simultaneous with liver transplant. Combined liver and kidney transplantation was probably the commonest combined organ transplant performed (6.8\% of all liver transplants in the United States). ${ }^{16}$ Hepatorenal syndrome together with preexisting kidney disease, are common indications for combined liver and kidney transplant; these include chronic glomerulonephritis, diabetic nephropathy, polycystic kidney disease, calcineurin inhibitor toxicity and hypertensive kidney disease. ${ }^{88}$ A study by Schmitt et al. ${ }^{89}$ demonstrated that patients with renal failure on hemodialysis had more survival benefit from combined liver-kidney transplants when compared with patients with renal failure but not on hemodialysis. For patients with renal failure but not on hemodialysis, there was no increase in survival when comparing combined liver-kidney transplants to liver transplants alone.

A well-established advantage of combined liver and kidney transplant is an immunoprotective effect of the transplanted kidney from the liver allograft when both organs come from the same donor. ${ }^{90,91}$ The possible mechanism has not been clearly elucidated, but it has been suggested that the liver absorbs lymphocytotoxic antibodies, promotes antibody phagocytosis by Kupffer cells, and secretes soluble human leukocyte antigens. A pretransplant crossmatch is not routinely performed and cases of conversion of a positive to a negative cross-match posttransplant have been described. The most common indication for combined liver and kidney transplant in children is inherited hepatic metabolic abnormalities such as primary hyperoxaluria. ${ }^{92}$ Kitajima et al. ${ }^{93}$ reported that a sequential liverkidney transplant from a single living donor achieved an excellent overall survival rate of $92.3 \%$ in 10 years.

Combined heart and liver transplant was described for patients with familial amyloid polyneuropathy (FAP). In this group of patients, the liver produces the majority of the transthyretin that is involved in the cause of amyloid deposition. ${ }^{94}$ Cardiac cirrhosis is the most common hepatic diagnosis in patients with coronary heart disease. ${ }^{17}$ Other indications of combined heart and liver transplant include familial hypercholesterolemia, beta-thalassemia, ${ }^{95}$ hemochromatosis, ${ }^{96}$ alcoholic cardiomyopathy, cryptogenic cirrhosis with underlying cardiomyopathy and glycogen 
storage disease. ${ }^{97}$ Combined liver and lung transplantation were reported to be performed in cystic fibrosis patients. ${ }^{98}$ Together with the experience and advancement, the use of liver transplant in these patients are likely to be expanded.

\section{Expanding graft availability in low deceased donor rate regions}

Despite high demand, a severe shortage of suitable allografts limits the use of liver transplant for the treatment of different etiologies of liver diseases. The condition in Asian centers including Hong Kong is different from Scandinavian countries described-having a surplus in liver grafts is a kind of luxury. Expanding the indications for liver transplant affects patients who were already on list. Resistance would be encountered if the outcome of new indications were not proven to be good enough. On the other hand, living donor liver transplant and multiple other strategies were developed to further increase organ supply. Close relatives are the commonest living donor but their $\mathrm{ABO}$ blood group may not be compatible. $\mathrm{ABO}$-incompatible living donor liver transplant protocols with the use of rituximab and plasma exchange were reported by multiple living donor liver transplant centers. ${ }^{99-101}$ Donor exchange programs were also aimed at resolving the incompatible relative problem. ${ }^{102,103}$ Domino liver transplant, with the example of FAP graft, were reported to have comparable short term results with deceased donor liver transplant. ${ }^{104}$ However, the de novo development of FAP within various periods has been described. ${ }^{105}$

Another strategy to expand the donor pool is utilization of extended criteria donor grafts, e.g. donation after circulatory death (DCD) ${ }^{106}$ steatotic, ${ }^{107}$ and elderly grafts, ${ }^{108,109}$ etc. Liver transplant service could only be expanded with the expansion of indication together with graft availability.

Although the number of cadaveric organ donations has not increased in most Asian places, South Korea has recently succeeded in increasing the rate of organ donation by introducing several systems, such as incentive programs, an organ procurement organization, a donor registry, and a system to facilitate potential donor referral. ${ }^{110}$ With these measures, the number of braindead donors increased from 50 in 2003 to 367 in 2013. This experience may help other Asian regions to improve their organ donation rates. ${ }^{111}$

\section{Extension of deceased donor criteria}

Extension of deceased donor criteria may be a potential method to expand liver transplant indications. Liver grafts from DCD are a potential source of organ growth in the West. Croome et al. ${ }^{112}$ compared DCD and donation after brain death (DBD) in terms of liver transplant recipient survival. The 1-, 3- and 5-year survival rates were $92.3 \%$,
$86.1 \%$ and $80.3 \%$ respectively in the DCD group and $92.3 \%, 85.1 \%$ and $79.5 \%$ respectively in the DBD group $(\mathrm{p}=0.27)$. The use of organs from DCD may be a method to alleviate organ shortages in Asian regions. DCD is still limited in Asia. However, in Mainland China, DCD has been the sole legal source of donor organs since 2015. A study found that DCD was associated with a higher risk of early allograft dysfunction. ${ }^{113}$ Future studies are required to evaluate the outcomes of DCD liver transplant and explore the possibility of adopting DCD grafts as a method of increasing graft supply in Asia.

\section{CONCLUSION}

The scope of indications for liver transplant has been gradually expanding over the decades. Going forward, further development of preoperative noninvasive predictors in tumor, patient and even donor factors is needed to identify patients at risk of poor outcomes. Stringently relaxed criteria for liver transplant will be the way to go. The significance of development of tools that can accurately predict outcomes lies not only in patient consultation and management but also in implementation of policies and guidelines in the future.

\section{CONFLICTS OF INTEREST}

No potential conflict of interest relevant to this article was reported.

\section{ORCID}

Kevin Ka-Wan Chu

https://orcid.org/0000-0001-7371-7633

Kelly Hiu-Ching Wong

https://orcid.org/0000-0003-3487-0197

Kenneth Siu-Ho Chok

https://orcid.org/0000-0001-7921-3807

\section{REFERENCES}

1. Chu KK, Chan SC, Sharr WW, Chok KS, Dai WC, Lo CM. Low-volume deceased donor liver transplantation alongside a strong living donor liver transplantation service. World J Surg 2014;38:1522-1528.

2. Jones PD, Hayashi PH, Barritt AS 4th. Liver transplantation in 2013: challenges and controversies. Minerva Gastroen- 
terol Dietol 2013;59:117-131.

3. Hashikura Y, Makuuchi M, Kawasaki S, et al. Successful living-related partial liver transplantation to an adult patient. Lancet 1994;343:1233-1234.

4. Lo CM, Fan ST, Liu CL, et al. Extending the limit on the size of adult recipient in living donor liver transplantation using extended right lobe graft. Transplantation 1997;63:15241528.

5. Strong RW, Lynch SV, Ong TH, Matsunami H, Koido Y, Balderson GA. Successful liver transplantation from a living donor to her son. N Engl J Med 1990;322:1505-1507.

6. Starzl TE, Groth CG, Brettschneider L, et al. Orthotopic homotransplantation of the human liver. Ann Surg 1968;168:392-415.

7. De Vreede I, Steers JL, Burch PA, et al. Prolonged diseasefree survival after orthotopic liver transplantation plus adjuvant chemoirradiation for cholangiocarcinoma. Liver Transpl 2000;6:309-316.

8. Sapisochin G, Rodríguez de Lope C, Gastaca M, et al. "Very early" intrahepatic cholangiocarcinoma in cirrhotic patients: should liver transplantation be reconsidered in these patients? Am J Transplant 2014;14:660-667.

9. Gedaly R, Daily MF, Davenport D, et al. Liver transplantation for the treatment of liver metastases from neuroendocrine tumors: an analysis of the UNOS database. Arch Surg 2011;146:953-958.

10. Le Treut YP, Grégoire E, Klempnauer J, et al. Liver transplantation for neuroendocrine tumors in Europe-results and trends in patient selection: a 213-case European liver transplant registry study. Ann Surg 2013;257:807-815.

11. Nguyen NT, Harring TR, Goss JA, O’Mahony CA. Neuroendocrine liver metastases and orthotopic liver transplantation: the US experience. Int J Hepatol 2011;2011:742890.

12. Hagness M, Foss A, Line PD, et al. Liver transplantation for nonresectable liver metastases from colorectal cancer. Ann Surg 2013;257:800-806.

13. Toso C, Pinto Marques H, Andres A, et al. Liver transplantation for colorectal liver metastasis: survival without recurrence can be achieved. Liver Transpl 2017;23:1073-1076.

14. Carrion AF, Aye L, Martin P. Patient selection for liver transplantation. Expert Rev Gastroenterol Hepatol 2013;7:571579 .

15. Couetil JP, Houssin DP, Soubrane O, et al. Combined lung and liver transplantation in patients with cystic fibrosis: a 4 1/2-year experience. J Thorac Cardiovasc Surg 1995;110:1415-1422.

16. Papafragkakis H, Martin P, Akalin E. Combined liver and kidney transplantation. Curr Opin Organ Transplant 2010;15:263-268.

17. Bryant R 3rd, Rizwan R, Zafar F, et al. Contemporary outcomes of combined heart-liver transplant in patients with congenital heart disease. Transplantation 2018;102:e67-e73.

18. Mazzaferro V, Regalia E, Doci R, et al. Liver transplantation for the treatment of small hepatocellular carcinomas in patients with cirrhosis. N Engl J Med 1996;334:693-699.

19. Mazzaferro V, Bhoori S, Sposito C, et al. Milan criteria in liver transplantation for hepatocellular carcinoma: an evidence-based analysis of 15 years of experience. Liver Transpl 2011;17 Suppl 2:S44-S57.

20. Yao FY, Ferrell L, Bass NM, et al. Liver transplantation for hepatocellular carcinoma: expansion of the tumor size limits does not adversely impact survival. Hepatology 2001;33:1394-1403.

21. Yao FY, Xiao L, Bass NM, Kerlan R, Ascher NL, Roberts JP. Liver transplantation for hepatocellular carcinoma: validation of the UCSF-expanded criteria based on preoperative imaging. Am J Transplant 2007;7:2587-2596.

22. Patel SS, Arrington AK, McKenzie S, et al. Milan criteria and UCSF criteria: a preliminary comparative study of liver transplantation outcomes in the United States. Int J Hepatol 2012;2012:253517.

23. Fan J, Yang GS, Fu ZR, et al. Liver transplantation outcomes in 1,078 hepatocellular carcinoma patients: a multi-center experience in Shanghai, China. J Cancer Res Clin Oncol 2009;135:1403-1412.

24. Lee SG, Hwang S, Moon DB, et al. Expanded indication criteria of living donor liver transplantation for hepatocellular carcinoma at one large-volume center. Liver Transpl 2008;14:935-945.

25. Mazzaferro V, Llovet JM, Miceli R, et al. Predicting survival after liver transplantation in patients with hepatocellular carcinoma beyond the Milan criteria: a retrospective, exploratory analysis. Lancet Oncol 2009;10:35-43.

26. Sugawara Y, Tamura S, Makuuchi M. Living donor liver transplantation for hepatocellular carcinoma: Tokyo University series. Dig Dis 2007;25:310-312.

27. Zheng SS, Xu X, Wu J, et al. Liver transplantation for hepatocellular carcinoma: Hangzhou experiences. Transplantation 2008;85:1726-1732.

28. Xu X, Lu D, Ling Q, et al. Liver transplantation for hepatocellular carcinoma beyond the Milan criteria. Gut 2016;65:1035-1041.

29. Xu X, Zheng SS, Liang TB, et al. Orthotopic liver transplantation for patients with hepatocellular carcinoma complicated by portal vein tumor thrombi. Hepatobiliary Pancreat Dis Int 2004;3:341-344.

30. Choi HJ, Kim DG, Na GH, et al. The clinical outcomes of patients with portal vein tumor thrombi after living donor liver transplantation. Liver Transpl 2017;23:1023-1031.

31. Choi JY, Yu JI, Park HC, et al. The possibility of radiotherapy as downstaging to living donor liver transplantation for hepatocellular carcinoma with portal vein tumor thrombus. 
Liver Transpl 2017;23:545-551.

32. Lee KW, Suh SW, Choi Y, et al. Macrovascular invasion is not an absolute contraindication for living donor liver transplantation. Liver Transpl 2017;23:19-27.

33. Ito T, Takada Y, Ueda M, et al. Expansion of selection criteria for patients with hepatocellular carcinoma in living donor liver transplantation. Liver Transpl 2007;13:1637-1644.

34. Kim JM, Kwon CH, Joh JW, et al. Expanded criteria for liver transplantation in patients with hepatocellular carcinoma. Transplant Proc 2014;46:726-729.

35. Shimamura T, Akamatsu N, Fujiyoshi M, et al. Expanded living-donor liver transplantation criteria for patients with hepatocellular carcinoma based on the Japanese nationwide survey: the 5-5-500 rule. A retrospective study. Transpl Int 2019;32:356-368.

36. Hameed B, Mehta N, Sapisochin G, Roberts JP, Yao FY. Alpha-fetoprotein level $>1000 \mathrm{ng} / \mathrm{mL}$ as an exclusion criterion for liver transplantation in patients with hepatocellular carcinoma meeting the Milan criteria. Liver Transpl 2014;20:945951.

37. Parikh ND, Waljee AK, Singal AG. Downstaging hepatocellular carcinoma: a systematic review and pooled analysis. Liver Transpl 2015;21:1142-1152.

38. Yao FY, Mehta N, Flemming J, et al. Downstaging of hepatocellular cancer before liver transplant: long-term outcome compared to tumors within Milan criteria. Hepatology 2015;61:1968-1977.

39. Bergquist A, von Seth E. Epidemiology of cholangiocarcinoma. Best Pract Res Clin Gastroenterol 2015;29:221-232.

40. Razumilava N, Gores GJ. Classification, diagnosis, and management of cholangiocarcinoma. Clin Gastroenterol Hepatol 2013;11:13-21.

41. $\mathrm{Hu} \mathrm{HJ}$, Mao H, Shrestha A, et al. Prognostic factors and long-term outcomes of hilar cholangiocarcinoma: a singleinstitution experience in China. World J Gastroenterol 2016;22:2601-2610

42. DeOliveira ML, Cunningham SC, Cameron JL, et al. Cholangiocarcinoma: thirty-one-year experience with 564 patients at a single institution. Ann Surg 2007;245:755-762.

43. Jarnagin WR, Fong Y, DeMatteo RP, et al. Staging, resectability, and outcome in 225 patients with hilar cholangiocarcinoma. Ann Surg 2001;234:507-517.

44. Kimura N, Young AL, Toyoki Y, et al. Radical operation for hilar cholangiocarcinoma in comparable Eastern and Western centers: outcome analysis and prognostic factors. Surgery 2017;162:500-514.

45. Meyer CG, Penn I, James L. Liver transplantation for cholangiocarcinoma: results in 207 patients. Transplantation 2000;69:1633-1637.

46. Robles R, Figueras J, Turrión VS, et al. Spanish experience in liver transplantation for hilar and peripheral cholangiocarci- noma. Ann Surg 2004;239:265-271.

47. Sudan D, DeRoover A, Chinnakotla S, et al. Radiochemotherapy and transplantation allow long-term survival for nonresectable hilar cholangiocarcinoma. Am J Transplant 2002;2:774-779.

48. Heimbach JK, Gores GJ, Nagorney DM, Rosen CB. Liver transplantation for perihilar cholangiocarcinoma after aggressive neoadjuvant therapy: a new paradigm for liver and biliary malignancies? Surgery 2006;140:331-334.

49. Rea DJ, Heimbach JK, Rosen CB, et al. Liver transplantation with neoadjuvant chemoradiation is more effective than resection for hilar cholangiocarcinoma. Ann Surg 2005;242:451-458.

50. Darwish Murad S, Kim WR, Harnois DM, et al. Efficacy of neoadjuvant chemoradiation, followed by liver transplantation, for perihilar cholangiocarcinoma at 12 US centers. Gastroenterology 2012;143:88-98.

51. Hong JC, Petrowsky H, Kaldas FM, et al. Predictive index for tumor recurrence after liver transplantation for locally advanced intrahepatic and hilar cholangiocarcinoma. J Am Coll Surg 2011;212:514-520.

52. Mantel HT, Westerkamp AC, Adam R, et al. Strict selection alone of patients undergoing liver transplantation for hilar cholangiocarcinoma is associated with improved survival. PLoS One 2016;11:e0156127.

53. Razumilava N, Gores GJ. Cholangiocarcinoma. Lancet 2014;383:2168-2179.

54. O’Grady JG, Polson RJ, Rolles K, Calne RY, Williams R. Liver transplantation for malignant disease: results in 93 consecutive patients. Ann Surg 1988;207:373-379.

55. Ringe B, Wittekind C, Bechstein WO, Bunzendahl H, Pichlmayr R. The role of liver transplantation in hepatobiliary malignancy: a retrospective analysis of 95 patients with particular regard to tumor stage and recurrence. Ann Surg 1989;209:88-98.

56. Goss JA, Shackleton CR, Farmer DG, et al. Orthotopic liver transplantation for primary sclerosing cholangitis: a 12-year single center experience. Ann Surg 1997;225:472-481.

57. de Mestier L, Lardière-Deguelte S, Brixi H, et al. Updating the surgical management of peritoneal carcinomatosis in patients with neuroendocrine tumors. Neuroendocrinology 2015;101:105-111.

58. Coppa J, Pulvirenti A, Schiavo M, et al. Resection versus transplantation for liver metastases from neuroendocrine tumors. Transplant Proc 2001;33:1537-1539.

59. Frilling A, Malago M, Weber F, et al. Liver transplantation for patients with metastatic endocrine tumors: single-center experience with 15 patients. Liver Transpl 2006;12:10891096.

60. Fan ST, Le Treut YP, Mazzaferro V, et al. Liver transplantation for neuroendocrine tumour liver metastases. HPB (Ox- 
ford) 2015;17:23-28.

61. Moris D, Tsilimigras DI, Ntanasis-Stathopoulos I, et al. Liver transplantation in patients with liver metastases from neuroendocrine tumors: a systematic review. Surgery 2017;162:525-536.

62. Mazzaferro V, Pulvirenti A, Coppa J. Neuroendocrine tumors metastatic to the liver: how to select patients for liver transplantation? J Hepatol 2007;47:460-466.

63. Mazzaferro V, Sposito C, Coppa J, et al. The long-term benefit of liver transplantation for hepatic metastases from neuroendocrine tumors. Am J Transplant 2016;16:2892-2902.

64. Yao JC, Hassan M, Phan A, et al. One hundred years after "carcinoid": epidemiology of and prognostic factors for neuroendocrine tumors in 35,825 cases in the United States. J Clin Oncol 2008;26:3063-3072.

65. Ferlay J, Steliarova-Foucher E, Lortet-Tieulent J, et al. Cancer incidence and mortality patterns in Europe: estimates for 40 countries in 2012. Eur J Cancer 2013;49:1374-1403.

66. Page AJ, Cosgrove DC, Herman JM, Pawlik TM. Advances in understanding of colorectal liver metastasis and implications for the clinic. Expert Rev Gastroenterol Hepatol 2015;9:245-259.

67. Moris D, Tsilimigras DI, Chakedis J, et al. Liver transplantation for unresectable colorectal liver metastases: a systematic review. J Surg Oncol 2017;116:288-297.

68. Mühlbacher F, Huk I, Steininger R, et al. Is orthotopic liver transplantation a feasible treatment for secondary cancer of the liver? Transplant Proc 1991;23(1 Pt 2):1567-1568.

69. Penn I. Hepatic transplantation for primary and metastatic cancers of the liver. Surgery 1991;110:726-734.

70. Hoti E, Adam R. Liver transplantation for primary and metastatic liver cancers. Transpl Int 2008;21:1107-1117.

71. Meyers RL, Tiao GM, Dunn SP, Langham MR Jr. Liver transplantation in the management of unresectable hepatoblastoma in children. Front Biosci (Elite Ed) 2012;4:1293-1302.

72. Gupta AA, Gerstle JT, Ng V, et al. Critical review of controversial issues in the management of advanced pediatric liver tumors. Pediatr Blood Cancer 2011;56:1013-1018.

73. Hackl C, Schlitt HJ, Kirchner GI, Knoppke B, Loss M. Liver transplantation for malignancy: current treatment strategies and future perspectives. World J Gastroenterol 2014;20:53315344.

74. Rodriguez JA, Becker NS, O’Mahony CA, Goss JA, Aloia TA. Long-term outcomes following liver transplantation for hepatic hemangioendothelioma: the UNOS experience from 1987 to 2005. J Gastrointest Surg 2008;12:110-116.

75. Lai Q, Feys E, Karam V, et al. Hepatic epithelioid hemangioendothelioma and adult liver transplantation: proposal for a prognostic score based on the analysis of the ELTR-ELITA registry. Transplantation 2017;101:555-564.

76. National Institutes of Health Consensus Development Con- ference Statement on the Clinical Applications of Biomaterials. November 1-3, 1982. Artif Organs 1983;7:260-265.

77. Emre S, Mor E, Schwartz ME, et al. Liver transplantation in patients beyond age 60. Transplant Proc 1993;25(1 Pt 2):1075-1076.

78. Oezcelik A, Dayangac M, Guler N, et al. Living donor liver transplantation in patients 70 years or older. Transplantation 2015;99:1436-1440.

79. Taner CB, Ung RL, Rosser BG, Aranda-Michel J. Age is not a contraindication for orthotopic liver transplantation: a single institution experience with recipients older than 75 years. Hepatol Int 2012;6:403-407.

80. Petrowsky H, Rana A, Kaldas FM, et al. Liver transplantation in highest acuity recipients: identifying factors to avoid futility. Ann Surg 2014;259:1186-1194.

81. Wilson GC, Quillin RC 3rd, Wima K, et al. Is liver transplantation safe and effective in elderly ( $\geq 70$ years) recipients? A case-controlled analysis. HPB (Oxford) 2014;16:1088-1094.

82. Ikegami T, Bekki Y, Imai D, et al. Clinical outcomes of living donor liver transplantation for patients 65 years old or older with preserved performance status. Liver Transpl 2014;20:408-415.

83. Aduen JF, Sujay B, Dickson RC, et al. Outcomes after liver transplant in patients aged 70 years or older compared with those younger than 60 years. Mayo Clin Proc 2009;84:973978.

84. Gil E, Kim JM, Jeon K, et al. Recipient age and mortality after liver transplantation: a population-based cohort study. Transplantation 2018;102:2025-2032.

85. Kuramitsu K, Egawa H, Keeffe EB, et al. Impact of age older than 60 years in living donor liver transplantation. Transplantation 2007;84:166-172.

86. Levy MF, Somasundar PS, Jennings LW, et al. The elderly liver transplant recipient: a call for caution. Ann Surg 2001;233:107-113.

87. Sharpton SR, Feng S, Hameed B, Yao F, Lai JC. Combined effects of recipient age and model for end-stage liver disease score on liver transplantation outcomes. Transplantation 2014;98:557-562.

88. Chava SP, Singh B, Zaman MB, Rela M, Heaton ND. Current indications for combined liver and kidney transplantation in adults. Transplant Rev (Orlando) 2009;23:111-119.

89. Schmitt TM, Kumer SC, Al-Osaimi A, et al. Combined liverkidney and liver transplantation in patients with renal failure outcomes in the MELD era. Transpl Int 2009;22:876-883.

90. Rana A, Robles S, Russo MJ, et al. The combined organ effect: protection against rejection? Ann Surg 2008;248:871879.

91. Simpson N, Cho YW, Cicciarelli JC, Selby RR, Fong TL. Comparison of renal allograft outcomes in combined liverkidney transplantation versus subsequent kidney transplan- 
tation in liver transplant recipients: analysis of UNOS Database. Transplantation 2006;82:1298-1303.

92. Chava SP, Singh B, Pal S, Dhawan A, Heaton ND. Indications for combined liver and kidney transplantation in children. Pediatr Transplant 2009;13:661-669.

93. Kitajima K, Ogawa Y, Miki K, et al. Longterm renal allograft survival after sequential liver-kidney transplantation from a single living donor. Liver Transpl 2017;23:315-323.

94. Siddiqi OK, Ruberg FL. Cardiac amyloidosis: an update on pathophysiology, diagnosis, and treatment. Trends Cardiovasc Med 2018;28:10-21.

95. Olivieri NF, Liu PP, Sher GD, et al. Brief report: combined liver and heart transplantation for end-stage iron-induced organ failure in an adult with homozygous beta-thalassemia. N Engl J Med 1994;330:1125-1127.

96. Robinson MR, Al-Kindi SG, Oliveira GH. Heart and heartliver transplantation in patients with hemochromatosis. Int J Cardiol 2017;244:226-228.

97. Beal EW, Mumtaz K, Hayes D Jr, Whitson BA, Black SM. Combined heart-liver transplantation: indications, outcomes and current experience. Transplant Rev (Orlando) 2016;30:261-268.

98. Arnon R, Annunziato RA, Miloh T, et al. Liver and combined lung and liver transplantation for cystic fibrosis: analysis of the UNOS database. Pediatr Transplant 2011;15:254264.

99. Ikegami T, Yoshizumi T, Soejima Y, Uchiyama H, Shirabe $\mathrm{K}$, Maehara Y. Feasible usage of ABO incompatible grafts in living donor liver transplantation. Hepatobiliary Surg Nutr 2016;5:91-97.

100. Lee CF, Cheng CH, Wang YC, et al. Adult living donor liver transplantation across ABO-incompatibility. Medicine (Baltimore) 2015;94:e1796.

101. Song GW, Lee SG, Hwang S, et al. ABO-incompatible adult living donor liver transplantation under the desensitization protocol with rituximab. Am J Transplant 2016;16:157-170.

102. Chan SC, Lo CM, Yong BH, Tsui WJ, Ng KK, Fan ST. Paired donor interchange to avoid $\mathrm{ABO}$-incompatible living donor liver transplantation. Liver Transpl 2010;16:478-481.

103. Jung DH, Hwang S, Ahn CS, et al. Section 16. Update on experience in paired-exchange donors in living donor liver transplantation for adult patients at ASAN Medical Center. Transplantation 2014;97 Suppl 8:S66-S69.

104. Marín-Gómez LM, Gómez-Bravo MA, Barrera-Pulido L, et al. Outcomes of domino liver transplantation: a single institution's experience. Transplant Proc 2010;42:644-646.

105. Stangou AJ, Heaton ND, Hawkins PN. Transmission of systemic transthyretin amyloidosis by means of domino liver transplantation. N Engl J Med 2005;352:2356.

106. Reich DJ, Mulligan DC, Abt PL, et al. ASTS recommended practice guidelines for controlled donation after cardiac death organ procurement and transplantation. Am J Transplant 2009;9:2004-2011.

107. Wong TC, Fung JY, Chok KS, et al. Excellent outcomes of liver transplantation using severely steatotic grafts from brain-dead donors. Liver Transpl 2016;22:226-236.

108. Akamatsu N, Sugawara Y, Tamura S, et al. Impact of live donor age $(>$ or $=50)$ on liver transplantation. Transplant Proc 2007;39:3189-3193.

109. Tanemura A, Mizuno S, Wada H, Yamada T, Nobori T, Isaji $S$. Donor age affects liver regeneration during early period in the graft liver and late period in the remnant liver after living donor liver transplantation. World J Surg 2012;36:11021111.

110. Lee SD, Kim JH. Changes in the organ procurement system in South Korea: effects on brain-dead donor numbers. Transplant Proc 2009;41:3551-3555.

111. Soyama A, Eguchi S. The current status and future perspectives of organ donation in Japan: learning from the systems in other countries. Surg Today 2016;46:387-392.

112. Croome KP, Lee DD, Perry DK, et al. Comparison of longterm outcomes and quality of life in recipients of donation after cardiac death liver grafts with a propensity-matched cohort. Liver Transpl 2017;23:342-351.

113. Zhou J, Wei Q, Zheng S, Xu X. Early allograft dysfunction after liver transplantation with donation after cardiac death donors. Hepatobiliary Surg Nutr 2019;8:566-568.

114. Unek T, Karademir S, Arslan NC, et al. Comparison of Milan and UCSF criteria for liver transplantation to treat hepatocellular carcinoma. World J Gastroenterol 2011;17:42064212.

115. Togashi J, Akamastu N, Kokudo N. Living donor liver transplantation for hepatocellular carcinoma at the University of Tokyo Hospital. Hepatobiliary Surg Nutr 2016;5:399-407.

116. Bonadio I, Colle I, Geerts A, et al. Liver transplantation for hepatocellular carcinoma comparing the Milan, UCSF, and Asan criteria: long-term follow-up of a Western single institutional experience. Clin Transplant 2015;29:425-433.

117. de Ataide EC, Garcia M, Mattosinho TJ, Almeida JR, Escanhoela CA, Boin IF. Predicting survival after liver transplantation using up-to-seven criteria in patients with hepatocellular carcinoma. Transplant Proc 2012;44:2438-2440.

118. Kaido T, Ogawa K, Mori A, et al. Usefulness of the Kyoto criteria as expanded selection criteria for liver transplantation for hepatocellular carcinoma. Surgery 2013;154:1053-1060.

119. Lei J, Yan L. Comparison between living donor liver transplantation recipients who met the Milan and UCSF criteria after successful downstaging therapies. J Gastrointest Surg 2012;16:2120-2125. 